\title{
e-Interview
}

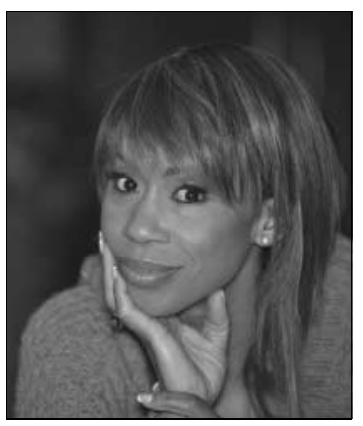

\section{Trisha Goddard}

Trisha Goddard was born in 1957 and is a successful television presenter and campaigner for mental health issues. Her youngest sister was diagnosed with schizophrenia and subsequently took her own life. Trisha is open about her history of mental health problems, which were precipitated by multiple personal traumas. She has recently made a full recovery from breast cancer.

We are used to looking at mental illness, what does 'mental wellness' look like? Resilience. The ability to bounce back. To learn from life. Mental wellness is about a sense of identity, purpose and connection.

\section{Looking back on your life, what have you learned and what would you do differently?}

Oh gosh. I'm still learning ... I've learned that every cloud, every hellish situation I've encountered, has a silver lining. It might take weeks, months or years to work out what the upside of a bad time might be, but it comes in the end. If I hadn't had to deal with the betrayal of my first husband hiding the fact that he was HIV positive, if I hadn't had to go through the experience of my second husband cheating on me with my researcher when I was pregnant and giving birth to our second daughter, I wouldn't have been able to deal with the man I'd called 'dad' revealing to me that my late mother had worked so hard at concealing the truth from me: that he wasn't my father and that almost 50 years of my doubting it wasn't because I was mad - it was because I was amazingly sane!

Plus, my 1994 breakdown (in Sydney, Australia) turned out to be the best thing that ever happened to me. I had to have therapy and as a result learned how to stop destructive tendencies and manage my life better instead of allowing myself to blunder into bouts of depression. It also meant learned valuable work/life balance.
Is the stigma regarding mental health issues changing?

Yes, slowly. It's often a case of two steps forwards and two steps back. But you can't be complacent. Every new generation needs to be reminded and often it's a different issue that needs to be destigmatised. I was dismayed to read Janet Street-Porter's recent article in The Daily Mail claiming that depression was a rich, middle class woman's illness and that it's something the working class and poverty-stricken don't get. Here we go again with that myth of the 'worried well' again - plus the confusing of clinical depression and general life angst.

Could the media be rightly accused of exploiting those with mental illness? Not in the way you'd think. Some may say that certain talent shows do that, but having been a mental health advisor to the Australian federal government for 10 years (1988-1998) representing mental health service consumers and carers, I'm very aware that people with mental illness have personalities too - with all the flaws and foibles the rest of us have. Are we going to say that just because someone has a diagnosis, they're not allowed to express a talent they think they have? I mean, plenty of those deemed 'normal' (a word I dislike!) do just that!

Is aTV show the most helpful forum for people to resolve difficult family issues? A TV show is a TV show. If I'm contracted to do a chat show, I'm going to do what I'm best at. I've trained in conflict resolution and been involved with mental health issues for almost half of my life so that's the area I choose to work in. I've always said that the day these services are freely available without waiting lists, inaccessibility and stigma is the day I won't have a show!

\section{How do you think psychiatrists} are perceived?

The most powerful determinant of a profession's status is the status of the people they serve. Like many other professions associated with mental illness (rather than mental wellness), the stigma experienced by the client group is shared by the professionals.

\section{Do you think we help carers enough?}

Absolutely not. Carers widely report being excluded, not listened too and unable to influence care plans when they are the ones involved in providing the framework for them.

What could we do differently?

Stop hiding behind the defence of

'confidentiality'. You may not be able to share a client's information with a carer, but that shouldn't prevent you from hearing the carer's story first hand. In Australia, many services started implementing a plan where both carer and service user have sat down together to negotiate care.

\section{A disproportionately small percentage of medical students aspire to be psychiatrists, and it isn't completely clear why that is. How could more be encouraged to join?}

After more than 20 years in TV, radio and print journalism, I can quite safely say that the vast majority of my profession don't really know the difference between psychologists and psychiatrists. Recently, psychologists have embraced the media and (albeit with mixed results) have 'got out there' and demonstrated to the public what it is they do and their range of skills. Ask any journalist or member of the public for the names of psychologists and they can rattle them off: Cary Cooper, Linda Papadopoulos, Oliver James - to name a few. Now ask them for names of psychiatrists and apart from Raj Persuad who no longer appears, they'd be at a loss. I feel that often psychiatric bodies are so hung up on status that they're a bit sniffy about appearing in the popular press. Whether you like it or not, it's how you communicate with the masses - and if you get the chance to do so, you have to be able to speak in laymen's terms. I've spoken to psychiatrists in the past who fear being looked down upon because they dare to communicate to the masses! Now, where do you think students get their ideas about psychiatrists from? They're still seen as being aloof and not being very communicative. It's not that this is necessarily true, but sorry folks - you can't spend so much time and energy on maintaining status that you forget how to be approachable outside your professional circles! And do psychiatrists visit schools to chat about what they do? I'd love to see a well-chosen group made up out of psychiatrists, psychologists, mental health service users, carers and mental health charities involved in a carefully thought-out, engaging programme visiting schools and/or universities.

\section{What qualities should the ideal} psychiatrist have?

Life experience. The ability to truly listen. Ability to work as part of a team (not necessarily as the 'head' of a team). Ability to deliver non-pharmaceutical interventions and experience of working outside of the $\mathrm{NHS}$ and/or private practice.

Dr Lucy Watkin

doi: 10.1192/pb.bp.110.031492 